\title{
Primer total diz artroplastisinde karşılaşılan patello-femoral sorunlar ve çözümleri
}

\author{
Management of patello-femoral problems in primary total knee arthroplasty
}

\author{
Hakkı Sur, Kayahan Kayıkçı, Semih Aydoğdu \\ Ege Üniversitesi Tıp Fakültesi, Ortopedi ve Travmatoloji Anabilim Dalı, İzmir
}

\begin{abstract}
Total diz artroplastisi sonrasında görülen komplikasyonlar arasında patello-femoral eklemi ilgilendirenler, gerek sıklık, gerekse de ciddiyeti yönünden enfeksiyon ya da instabilite gibi diğer bazı komplikasyonlar kadar popüler değildir. Patello-femoral eklem, cerrahlar tarafindan primer total diz artroplastisi sırasında çeşitli gerekçelerle biraz ihmal edilen bir eklem olduğu gibi, sorunları da genellikle küçümsenmektedir. Bu komplikasyonların spektrumu; multifaktöriyel olarak kabul edilen ama en çok patello-femoral eklem ile ilişkilendirilen ve nispeten yaygın bir sorun olan diz önü ağrısından, patellar kırık ve çıkığa kadar uzanan değişik ağırlıktaki çok sayıda komplikasyonu içeren geniş bir yelpazede bulunmaktadır. Total diz artroplastisi sonrası karşılaşılan patello-femoral eklem kökenli sorunlara yalnızca patella ve patellar komponent ile ilişkili olarak yapılan cerrahi uygulamalar değil, diğer kemiklerde yapılan işlemler; tibio-femoral eklemi ilgilendiren işlem ve uygulamaların da yol açabileceği unutulmamalıdır. Erken tasarım total diz artroplastilerinde çok daha sık olarak bu sorunlarla karşılaşılırken, zamanla protez tasarımları ve cerrahi teknikteki gelişmelerin etkisiyle oransal olarak düşmüştür. Ancak günümüzde de, patellofemoral eklem kökenli sorunlar bazen çözümü güçlük gösterebilen, ağır revizyon girişimlerini gerektirebilen, total diz artroplastisinin sonucunun kalitesini önemli ölçüde etkileyebilen sorunlar olmaya devam etmektedir.
\end{abstract}

Anahtar sözcükler: patello-femoral ağrı; patello-femoral instabilite; total diz artroplastisi
Complications related to the patellofemoral joint seen after total knee arthroplasty are not as popular as some other complications in regard to frequency and majority such as infection or instability. As the patellofemoral joint is somehow neglected by surgeons on various grounds during primary total knee arthroplasty, its problems are also often underestimated. The spectrum of these complications has a wide range: from anterior knee pain -which is considered to be multifactorial but most commonly associated with patellofemoral joint- to patellar fracture and dislocation. It should be noted that patellofemoral joint-induced problems encountered after total knee arthroplasty are not only caused by surgical operations on patella and patellar components, but also by applications on other bones and procedures related to the tibio-femoral joint. While these problems were encountered more frequently in early design total knee arthroplasties, they decreased in proportion to the developments in prosthesis design and surgical technique. However, even nowadays, patellofemoral joint originated problems can be sometimes difficult to solve, may require severe attempts of revision, and also significantly affect the quality of total knee arthroplasties' results.

Key words: patello-femoral pain; patello-femoral instability; total knee artroplasty

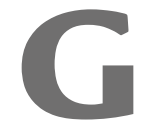

ünümüzde, total diz artroplastisi (TDA) sonrasında görülen komplikasyonlar arasında patello-femoral eklemi (PFE) ya da bir bütün olarak diz ekstansör mekanizmasını ilgilendirenler, gerek sıklık gerekse de ciddiyeti yönünden, enfeksiyon veya instabilite gibi diğer bazı komplikasyonlar kadar popüler değildir. Buradaki ana neden; sık görülen bazı
PFE kökenli sorunların (örneğin diz önü ağrısı ya da patello-femoral ağrı) hastalar tarafindan tolere edilebilmesi ve cerrahlarca sıklıkla revizyon endikasyonu olarak görülmemesi; cerrahi girişim gerektiren PFE kökenli sorunlarla ise (ekstansör mekanizma yırtıkları, patello-femoral instabilite) nispeten az sıklıkla karşılaşılmasıdır.

- İletişim adresi: Prof. Dr. Hakkı Sur, Ege Üniversitesi Tıp Fakültesi, Ortopedi ve Travmatoloji Anabilim Dalı, İzmir, Türkiye Tel: 0232 - 3427805 e-posta: nejat.hakki.sur@ege.edu.tr

- Geliș tarihi: 19 Aralık $2018 \quad$ Kabul tarihi: 19 Aralık 2018 
TDA sonrasında görülebilen patello-femoral (PF) komplikasyonların spektrumu; multifaktöriyel olarak kabul edilen ama en çok PFE ile ilişkilendirilen ve nispeten yaygın bir sorun olan diz önü ağrısından, patellar kırık ve çıkığa kadar uzanan değişik ağırıktaki çok sayıda komplikasyonu içeren geniş bir yelpazede bulunmaktadır.

PFE, primer TDA sırasında cerrahlar tarafından çeşitli gerekçelerle biraz ihmal edilen bir eklem olduğu gibi, sorunları da genellikle küçümsenmektedir. Her ne kadar bir revizyon girişimine başvurulmaması biraz hafifletici gibi görünmekle birlikte; ağrı ve günlük yaşam işlevlerinde kısıtlılığa yol açması nedeniyle TDA'dan elde edilecek sonucun kalitesi olumsuz etkilenebilmektedir.

TDA sonrası karşılaşılan PFE kökenli sorunlara yalnızca patella ve patellar komponent ile ilişkili olarak yapılan cerrahi uygulamalar değil, diğer kemiklerde yapılan işlemler; tibio-femoral eklemi ilgilendiren işlem ve uygulamaların da yol açabileceği unutulmamalıdır. Bu nedenle, PFE kökenli olduğu düşünülen sorunların giderilmesi için revizyon planlandığında, yalnızca ekstansör mekanizma değil, TDA'nın tümü dikkate alınmalıdır. Hatta denilebilir ki, TDA sonrası diz ekstansör mekanizmasını ilgilendiren bir komplikasyon, sıklıkla femoral ve/veya tibial komponentteki bir sorunun göstergesidir. Bu bölümde; primer TDA sonrası görülen PF sorunların epidemiyolojisinden bahsedilecek, ardından sık ama benign bir sorun olarak görülen diz önü ağrısından (PF ağrı) ve bu komplikasyonla PFE yüzey replasmanı yapılması arasındaki ilişki üzerinde durulacak; sonrasında hastalar ve cerrahlar açısından daha sıkıntılı bir komplikasyon olarak görülen patellofemoral instabilitenin (PFi) nedenleri, tanısı ve tedavi yöntemleri tartışılacak; nihayet PFE kökenli diğer daha az görülen sorunlardan bahsedilecektir. Kuadriseps ve patellar tendon yırtıkları ile patella kırıklarından bir önceki bölümde bahsedildiğinden, bu bölümde bahsedilmeyecektir.

\section{EPIDEMIYOLOJi}

Primer TDA sonrası görülen komplikasyonlar arasında PFE kökenli olanların oranı tartışmalıdır. Bu tartışmanın en önemli nedeni, komplikasyon oranlarının revizyon oranları üzerinden hesaplanmaya çalışılmasıdır. Enfeksiyon, instabilite, gevşeme gibi sorunlarda komplikasyon oranı ile revizyon oranı arasında bir paralellik varken, PFE kökenli komplikasyonlarda bu paralelliğin olmaması, PFE kökenli komplikasyonların daha düşük oranlarda tanımlanmasına yol açmıştır. Oysa, Vince'in güncel bir yorum yazısında, başarısız TDA'nın en sık sekiz nedeni arasında "patella \& malrotasyon" başlığı da yer almaktadır. ${ }^{[1]}$
TDA'nın “erken-komplikasyon” çağı olarak bilinen 70'li ve 80'li yıllarda, tüm komplikasyonlar gibi, PFE kökenli olanlarla da sıklıkla karşılaşılmaktaydı. Hatta, o dönemde primer TDA sonrası görülenler, komplikasyonlar içinde oransal olarak önemli bir bölümü oluşturmaktaydı. Erken dönem çalışmalarda, \%50 gibi yüksek PFE kökenli komplikasyon oranları bildirilmiştir. ${ }^{[2]} \mathrm{Bu}$ kadar yüksek oranlardan, erken TDA'lardaki tasarım sorunları ve cerrahi teknikteki eksiklikler büyük oranda sorumludur. Yine o dönemde, pek çok TDA'nın patellar yüzey değişimi için uygun enstrümantasyon ve komponentlere sahip olmaması yüzünden ve ayrıca femoral tasarım eksikliklerinin de etkisiyle yüksek oranda diz önü ağrısı sorunuyla karşılaşılmıştır.

Zamanla, gerek tasarımlardaki gerekse cerrahi teknikteki iyileştirmeler sayesinde, primer TDA sonrası yaşanan PFE kökenli sorunların oranları oldukça gerilemiş, komplikasyonların niteliği de değişikliğe uğramıştır.

Primer TDA sonrası komplikasyon oranlarının belirlenmesinde revizyon nedenleri oranlarının kullanılması, PFE kökenli komplikasyonları belirlemede sorun oluşturmaktadır. Öyle ki, en geniş sayıda revizyon olgusunu içeren Amerikan Sağlık Sistemi (NIS) kayıtlarında da, ABD dışındaki altı ülkenin kayıt sistemlerinin ortak değerlendirmesinde de, primer TDA sonrası revizyon nedenleri arasında enfeksiyon ve mekanik gevşeme en başta yer almakta; PFE'yi özgün olarak belirleyen hiçbir komplikasyon bulunmamaktadır. ${ }^{[3,4]}$ Bunda, PFE kökenli sorunlarda revizyona başvurma oranının nispeten daha düşük olmasının yanı sıra, bu sorunların özgün değil de genel adlarla (çıkık, osteoliz, yüklenme yüzeyi aşınması, implant başarısızlığı, periprostetik kırık vb.) yer alması muhtemelen önemli rol oynamaktadır. Ancak yine de, bu tanımlayıcı çalışmalarda, tüm TDA revizyonlarının \%5'inde izole patellar komponente ilişkin revizyon girişimi yapıldığı bildirilmektedir. ${ }^{[3]}$ Deneyimli merkez kökenli çalışmalarda, PFE kaynaklı revizyon oranları \%1'in de altında bildirilmektedir.

Günümüzde, TDA sonrası PFE kökenli sorunları geniş kapsamlı olarak değerlendiren çalışmalarda komplikasyon oranı \%1-12 arasında, bunlara bağlı reoperasyon oranı da \%4 civarındadır. ${ }^{[5]}$

Epidemiyolojiye ilişkin belirtilmesi gereken son bir nokta da; PFE kökenli sorunlar nedeniyle yapılan revizyon girişimlerinden sonra da re-operasyon/re-revizyon oranının yüksek olmasıdır. Mayo Klinik'in -erken dönem tasarım ve teknikle TDA uygulanmış olguları da içermekle birlikte- ekstansör mekanizma kökenli komplikasyonlara yönelik revizyon çalışmasında bu durum ortaya konmuştur. ${ }^{[6]}$ 


\section{TOTAL DIZ ARTROPLASTISI VE PATELLO-FEMORAL EKLEM}

TDA'nın sonuçları itibariyle önemli bir belirleyicisi olan diz ekstansör mekanizmasına, TDA cerrahi tekniğinde genellikle daha az özen gösterilmekte; hatta ihmal edilmektedir. Patellar komponent ile yüzey yenilemesi yapılan ve yapılmayan TDA'lar arasındaki çelişkili meta-analiz sonuçları, cerrahların patella ve ekstansör mekanizma konusundaki ihmalkârlı̆̆ını daha da arttırmaktadır. ${ }^{[7-11]}$ Doğal ve yüzey yenilemesi yapılan patella, mekanik özelliklerinin sonucu olarak patellar kayma (maltracking), temas alanı ve stresin yayılımı açısından birbirinden farklılık gösterir. Yüzey yenilemesi yapılan patellanın daha küçük bir temas alanına sahip olması, bu nedenle PFE'deki stres ve yüklenmenin artması dezavantaj olarak görülebilir.

Kas gücünün yanında bazı cerrahi faktörler de TDA sonrası kuadriseps fonksiyonunu etkiler. Bu faktörlerden biri de cerrahi yaklaşımdır. Yaygın olarak kullanılan standart mediyal parapatellar yaklaşım, enstrümantasyon için uygun açıklığı sunar; ancak midvastus ve subvastus yaklaşım ile karşılaştırıldığında, standart mediyal parapatellar yaklaşımın daha fazla lateral retinakuler gevşetme oranları ile ilişkili olduğu gösterilmiştir. Bu yaklaşım ile ekstansör mekanizmanın bütünlüğü bozulduğundan, eğer tamir suboptimal yapılırsa patellar kayma problemleri ortaya çıkabilir. ${ }^{[12]}$ Subvastus yaklaşım ile mediyal ekstansör mekanizma da korunduğu için, erken ameliyat sonrası dönemde kuadriseps kas gücü daha yüksektir. Ancak uzun dönemde, subvastus ve standart yaklaşım uygulananlar arasında kuadriseps kas gücü açısından anlamlı bir fark gözlenmemiştir. Erken ameliyat sonrası dönemdeki bazı avantajlarına rağmen, subvastus yaklaşımın kilolu ve kaslı hastalarda birtakım teknik zorlukları vardır. Bu zorluklar eğitim ile aşılır.

TDA artroplastisi ve PF mekanizmanın yönetiminde en çok tartışma patellar eklem yüzeyinin değiştirilmesi üzerine yapılmıştır. Patellar eklem yüzeyinin değiştirilme oranları üzerine 2004-2014 yılları arasında yapılmış bir derlemede, Norveç'te \%4'ten, ABD'de \%82'ye kadar geniş aralıkta sonuçlar bildirilmiştir. ${ }^{[13]}$ Patellar eklem yüzeyini değiştirmenin amacı, etiyolojisinin multifaktöriyel olduğu düşünüldüğü halde diz önü ağrısını azaltmaktır. Ancak bununla birlikte, patellar eklem yüzeyinin değiştirilmesinden kaynaklanan patellar kayma, patellar komponent aşınması, osteoliz, aseptik nekroz, implant yetmezliği, patella fraktürü ve gevşeme gibi komplikasyonların da özellikle erken dönem TDA tasarımlarında arttığı görülmüştür. Bu komplikasyonlar, cerrahların patellar eklem yüzeyini değiştirmekten çekinmelerine neden olur. Ayrıca, patellar implant uygulaması; eğitim, teknik bilgi, uygun enstrümantasyon ve zaman gerektiren bir işlemdir.
PFE yüzeyi için, kubbe şeklinde, anatomik veya hareketli gibi birkaç farklı implant üretilmiştir. Kubbe şeklindeki implantlar, pozisyon hatalarını daha çok tolere edip küçük yanlışları kompanse edebilir olduğundan, günümüzde en sık tercih edilen patellar komponent tasarımını oluşturmaktadır.

Patellar yüzey yenilemesi yapılan ve yapılmayan hastaların fonksiyonel durumları karşılaştırıldığında çelişkili sonuçlar bildirilmektedir. Yirmi randomize kontrollü çalışmanın derlenip 2.573 hastanın değerlendirildiği bir meta analizde, patellar eklem yüzeyinin değiştirildiği hastalarda, takip sürecinin bir yıldan iki yıla kadar olan bölümünde, Diz Cemiyeti Skoru'nun (KSS) anlamlı olarak daha yüksek olduğu görülmüştür. Diğer taraftan, takip sürecinde 2. yıldan sonra anlamlı farklılık gözlenmemiştir. ${ }^{[14]}$

\section{TDA'DA PFE SORUNLARI YÖNÜNDEN RISK FAKTÖRLERI}

TDA olgularında; ameliyat öncesindeki, ameliyat sırasındaki ve hastaya bağlı faktörlerin PFE kökenli komplikasyon riskini arttırabileceği akılda tutulmalıdır.

\section{Hasta seçimi:}

a. Bozuk PF dizilim ve stabilite: TDA öncesinde de PF dizilimi ve stabilitesi bozuk olan olgularda TDA sonrasında başta ağrı olmak üzere dizilim ve stabilite sorunları ile çok daha sık olarak karşılaşılmaktadır. İleri derecede valgus dizilimli olgularda da bu tür sorunlara yatkınlık söz konusudur.

b. Geçirilmiş cerrahi girişim: Daha öncesinde yüksek tibial osteotomi ya da tuberositas tibia osteotomisi geçirmiş olgularda, infrapatellar skar dokusu gelişimine bağlı patella baja varlığı, PFE kökenli sorunlarla karşılaşma riskini arttırmaktadır.

c. Sistemik hastalıklar: Obezite, inflamatuvar hastalıklar, uzun süreli steroid kullanımı ve diyabet varlığında, PFE kökenli sorunlarla karşılaşma riski artmaktadır.

\section{Protez tasarımı:}

a. Posterior stabilize tasarım: Özellikle "patellar clunk sendromu" gibi sorunlar yalnızca bu tasarım TDA'lara özgüdür.

b. Femoral komponent: Patellar oluğu sığ ve simetrik olan femoral komponentlerde başta diz önü ağrısı, instabilite, patellar stres kırığı gibi sorunlar daha sık görüldüğü için modern tasarım TDA'larda asimetrik ve daha derin patellar oluklu femoral komponentler bulunmaktadır. 
c. Metal arkalıklı patellar komponent: TDA'nın erken döneminde moda olan bu tür komponentler, yüksek komplikasyon riski nedeniyle günümüzde hemen hemen terk edilmişlerdir.

d. Onset-inset tasarım: İnset olarak yerleştirilen patellar komponentler ile stabilite sorunları azaldığından, daha az PFE kökenli soruna yol açmaktadır.

\section{Cerrahi teknik:}

a. Komponentlerin yerleşimi: Özellikle patellar ve femoral komponentler başta olmak üzere her üç komponentin de translasyonel ve rotasyonel konumlandırılması, PFE kinematiğini ve kinetiğini önemli ölçüde etkileyebilmektedir. PFE dizilimi bakımından risk (gezinim bozukluğu, subluksasyon, çıkık) oluşturan komponent yerleşimleri Tablo 1'de gösterilmiştir.

b. Cerrahi yaklaşım tipi: Kuadriseps mekanizmasının daha fazla korunmasına olanak veren subvastus ya da midvastus yaklaşımları PFE kökenli sorunları azaltabilmektedir.

c. Lateral gevşetme gereksinimi: Patellar dizilim ve yönelimi dengelemek için lateral retinakuler gevşetme kullanımı, PFE kökenli sorunlarla karşılaşma riskini arttırmaktadır.

d. Patella rezeksiyon miktarı: Patellanın önarka plandaki kalınlığının kritik bir eşiğin $(\sim 12 \mathrm{~mm})$ altına inecek şekilde rezeksiyonu, PFE kökenli sorunlarla karşılaşma riskini arttırmaktadır.

Tablo 1. TDA sonrasında PFE sorunları bakımından risk taşıyan komponent yerleşimleri

$\begin{array}{ll}\text { Eklem hattı } & \text { Yükselme } \\ & \text { Alçalma }\end{array}$

Femoral komponent

Mediyalize

İç rotasyon

Anteriorize

Fleksiyonda

Gerekenden büyük komponent

Tibial komponent $\quad$ İç rotasyon

Anteriorize

Patellar komponent

Lateralize

Kalınlık artması

Kalınlık azalması

Asimetrik yerleşim

\section{TOTAL DIZ ARTROPLASTISI SONRASI DiZ ÖNÜ AĞRISI}

Diz önü ağrısı, total diz artroplastisi sonrası en yaygın olarak karşılaştığımız inatçı diz problemidir. Bu durum, patellar eklem yüzeyi değiştirilsin veya değiştirilmesin (oransal olarak değişmekle birlikte) tüm TDA'larda görülebilmektedir. Nedeni tek değil çok sayıda faktöre bağlanması gereken bir sorundur (multifaktöriyeldir). Ancak, patellar yüzey değişimi yapılmayan olgularda, neden olarak öncelikle bu eksiklik sorumlu tutulmaktadır.

Patellar yüzey değişimi yapılmış 1596 ve yapılmamış 1717 TDA olgusunun değerlendirildiği oldukça güncel bir meta-analizde; patellar yüzey değişimi yapılmış olgularda diz önü ağrısı oranı \%8 (128/1596) bulunmasına karşın yüzey değişimi yapılmamış olgularda \%15,9 (273/1717) bulunmuştur. Aynı çalışmada, PFE kökenli komplikasyonlara bağlı revizyon oranı ise; patellar yüzey değişimi yapılmış olgularda \%1 (17/1636) oranında bulunurken, yüzey değişimi yapılmamış olgularda \%6,9 (135/3335) bulunmuştur. Sonuç olarak; diz önü ağrısı ve re-operasyon oranının, patella eklem yüzeyi değiştirilmiş hastalarda istatistiksel olarak anlamlı şekilde azaldığı tespit edilmiştir. Patellar yüzey değişimi sonrası yapılan revizyonların \%41'i (7/17) patellar komponent yetmezliği, \%35'i (6/17) inatçı diz önü ağrısı, \%12'si (2/17) patella kırığı, \%12'si (2/17) ise patellar subluksasyon veya kayma nedeniyledir. ${ }^{[15]}$

Patella eklem yüzeyi değiştirilmemiş hastalar, genellikle merdiven çıkma gibi aktiviteler sırasında diz önü ağrısından yakınmaktadırlar. Eğer hasta diz önü ağrısından yakınıyorsa, ameliyat sonrası radyografi ne kadar kusursuz olursa olsun hastanın memnuniyeti azalmaktadır. ${ }^{[8]}$

Diz önü ağrısının kaynağı ekstansör aparatın insersiyosu ve lateral retinakulum olarak kabul edilmektedir. Diz önü ağrısı nedenleri mekanik ve fonksiyonel nedenler olarak ikiye ayrılabilmektedir. Öncelikle altta yatan bir enfeksiyon olasılığı ekarte edildikten sonra fonksiyonel nedenler araştırılmalıdır. Kas, yumuşak doku dengesizliği ve dinamik valgus dizilimi, fonksiyonel nedenlerdendir. Valgus dizilimine; femoral ve tibial komponentlerin yanlış yerleştirilmesi dışında, eşlik edebilecek kalça artrozuna bağlı kalça abduktorları ve eksternal rotatorlarındaki zayıflık da neden olabilmektedir. Femoral komponentin iç rotasyonu da, kalça abduktorlarında zayıflığa neden olabilen bir diğer faktördür. Ayak arkası eversiyonu veya pes planovalgus da tibial iç rotasyona neden olarak dinamik valgusa yol açabilmektedir. Ayrıca ek olarak, lomber vertebra rahatsızlığı olan hastalarda artan pelvik tilt, dizde fleksiyon ile kompanse edilmeye çalışılmakta ve PFE'de stres artmaktadır. Bu da "diz-bel sendromu" olarak adlandırılmaktadır. ${ }^{[16]}$ 
Mekanik nedenler ise; PF veya tibiofemoral instabilite, protez yetmezliği, patella baja, patellar kondroliz veya osteoartrit, komponentlerin rotasyonel hataları, avasküler nekroz, patellar kırık, PF “clunk” sendromu veya sagittal planda ekstansör mekanizma basıncını arttıran diğer nedenlerdir. Bunlar içinde değişik düzeylerdeki PFi diz önü ağrısının saptanabilen en sık nedenidir.

Patellar kalınlığın restorasyonu ve uygun femoral komponent boyu da PFE'de oluşan rotasyonel momenti etkilemektedir. Patellar eklem yüzeyinin değişimi sonrası patellar kalınlık veya anterior femoral yükseklik azalırsa, kuvvet kolu dizin rotasyon merkezine yaklaşacak, bu nedenle kurvet kolu kısalacaktır. Dengeyi tekrar kurmak için kuadriseps kası tarafindan oluşturulan kuvvetin arttırılması gerekmektedir ki bu da diz önü ağrısı gelişimi ile ilişkilidir. ${ }^{[12]}$

Son meta-analizlerde, arka çapraz bağı koruyan ile posterior stabilizan protezler arasında ameliyat sonrası ağrı açısından anlamlı bir fark olmadığı bulunsa da; posterior stabilizan protezler daha az PF basınca neden olmaktadır. Ameliyat sonrası posterior instabilitesi ve diz önü ağrısı olan hastalarda bu durum dikkate alınmalıdır. ${ }^{[17,18]}$

TDA sonrasında inatçı diz önü ağrısı nedeni ile sekonder patellar eklem yüzeyi değiştirilen hastalardaki sonuçlar, primer TDA sırasında yüzey değişimi yapılmış olanlar kadar başarılı olmamaktadır. Sekonder patellar eklem yüzeyi değiştirilen 46 hastanın sadece 19'unda (\%41) ameliyat sonrası diz önü ağrısının gerilediği gözlenmiştir. Ancak, bu 19 hastadan 14'ü semptomlarındaki gerilemenin geçici olduğunu belirtmiştir. Sadece beş hastada kalıcı bir gerileme elde edilebilmiştir. Bu çalışmada sadece 16 (\%35) hasta sonuçtan memnun kaldığını ifade etmiştir. Hasta memnuniyet oranı ve diz önü ağrısının gerileme oranındaki farklılığın nedeni, üç hastanın ağrılarındaki gerilemeye rağmen memnun kalmamasıdır. Sonuç olarak; sekonder patellar yüzey değişimi sonrası, klinik ve fonksiyonel bazı iyileşmelere rağmen yüksek oranda diz önü ağrısının sebat ettiği, sekonder girişimden tatmin oranlarının düşük olduğu tespit edilmiştir. ${ }^{[19]}$

TDA sonrası gelişen/süregiden diz önü ağrısının tedavisinde, önce altta yatabilecek bir enfeksiyon varlığı ekarte edildikten sonra mekanik nedenler araştırılmalıdır. Mekanik nedenlerde cerrahi tedavi endike olabilmektedir. Uygulanabilecek cerrahi dışı tedavi yöntemleri arasında; sadece kuadriseps kasına yönelik değil, dinamik valgus dizilimini yenmek için aynı zamanda kalça abduktorlarına ve gövde kaslarına yönelik rehabilitasyon uygulanması yer almaktadır. Bandajlama, taping ve breys kullanımı da dinamik valgus dizilimini düzeltip patellar dizilim bozukluğunu giderebilmek için kullanılabilir.

\section{PATELLO-FEMORAL INSTABILITE}

PFi, TDA sonrası belirgin ağrıya ve fonksiyonel kısıtlıığa neden olarak revizyon gerektirebilecek önemli bir nedendir. ${ }^{[20]}$ Hastaların PFi ile ilgili en sık başvuru şikâyeti, dizde belirgin bir çıkık tarifinden ziyade, özellikle merdiven çıkma ve sandalyeden kalkma gibi zorlu aktiviteler sırasında diz önü ağrısı, krepitasyon ve güvensizlik/ boşalma hissidir. Hastaların az bir kısmı da hareket sırasında çıkık hissi tarif edebilir. Fakat, ağrısız giden bir dönemden sonra ani başlayan ağrıda, daha çok implant yetmezliği ve patellar kırık akla getirilmelidir. Erken dönem TDA tasarımlarında \%27 gibi yüksek oranda bildirilen bu komplikasyon günümüzde tasarımlar ve teknikteki gelişmelerin etkisiyle oldukça azaltılmıştır.

\section{Risk Faktörleri ve Oluş Mekanizması}

Normal anatomik, mekanik ve dinamik dengenin bozularak Q (kuadriseps) açısının arttığı, lateral gerginliğin oluştuğu her türlü durum, patellar instabiliteye neden olabilir. Hastaya ilişkin risk faktörleri; ameliyat öncesi dönemde valgus deformitesi, displastik troklea, instabilite veya patellar kayma sorunlarının varlığıdır. Cerrahi sırasında komponent yerleşimine ve boyutlarına ilişkin bozukluklar TDA sonrası patellar instabilitenin en sık nedenidir. Uygun kesiler yapılmış olsa bile, sementleme ve yerleştirilme aşamasında da hatalar ortaya çıkabilmektedir. Her üç komponentin de yerleşimine ilişkin bozukluklar, özellikle rotasyonel planda olanlar PFi'ye neden olabilir.

Femoral komponent tasarımında femoral oluğun derinliği ve lateral kenarın yüksekliği önem taşımaktadır. Femoral komponentin transepikondiller eksene göre iç rotasyonda ve mediyalize yerleştirilmesi $Q$ açısını, lateral yumuşak dokulardaki gerginliği ve nihayetinde laterale subluksasyonu arttırır. Bu nedenle, ameliyat sırasında femoral komponent ılımlı dış rotasyonda ve mümkün olduğunca lateralize yerleştirilmelidir. Berger ve ark.'nın çalışmasına göre; femoral ve tibial komponentin iç rotasyon toplamı $1-4^{\circ}$ olduğu zaman patellada lateral gezinim ve tilt, $3-8^{\circ}$ olduğu zaman subluksasyon, $7-17^{\circ}$ olduğu zamansa patellar çıkık ve başarısızlık oluşmaktadır. ${ }^{[21]}$ Femoral kesi yapilırken rotasyon derecesini belirlemede transepikondiller eksen, posterior kondiller eksene göre daha tutarlıdır. Anterior ve posterior femoral kesiler sırasında posterior kondiller eksen kılavuz alındığında, dizlerin \%45'inde en az $3^{\circ}$ rotasyonel hatalara neden olduğu belirlenmiştir. Bilgisayar yardımlı navigasyonlu olarak uygulanan total diz artroplastilerinde komponentlerin rotasyonel konumlandırılmasının daha iyi olduğu; ancak, bunun klinik ve fonksiyonel sonuçlarda anlamlı farklılık oluşturmadığı bildirilmiştir. ${ }^{[22]}$ Femoral kesi sonrası, distal femur ön yüzünde kuyruklu piyano görünümünün elde 

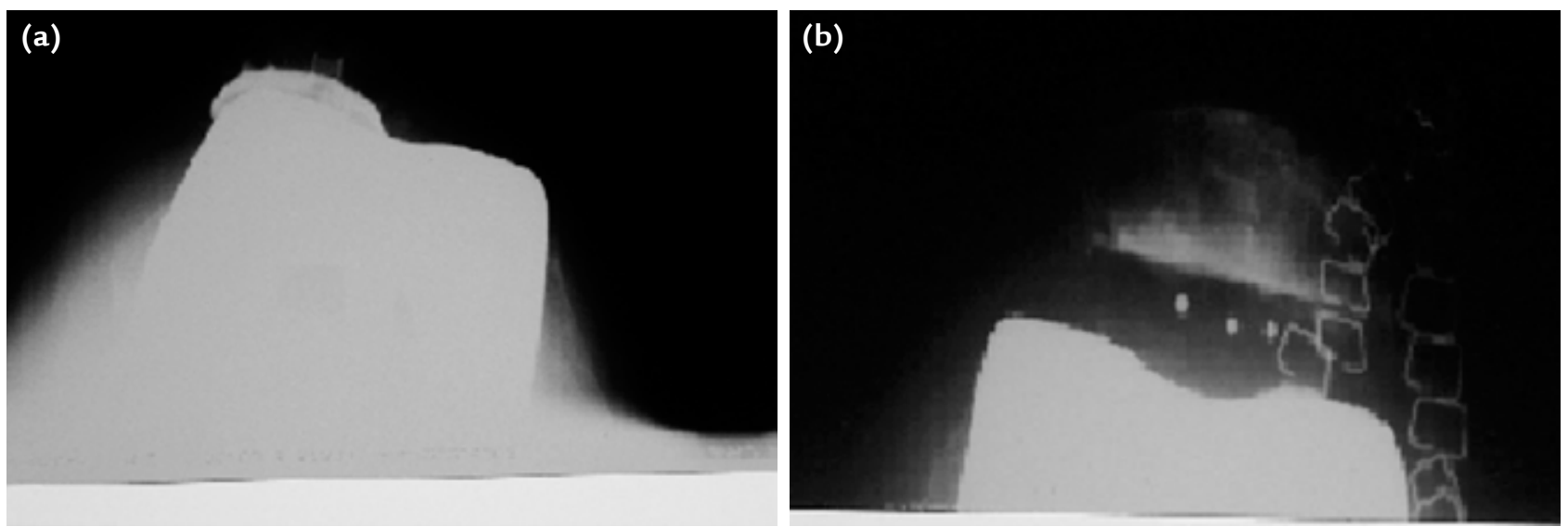

Şekil 1. a, b. TDA sonrası patellofemoral instabilite gelişmiş olgunun tanjansiyel grafisinde metal arkalıklı patellar implant uygulanmış patellanın laterale çıkığı (a). Aynı hastanın yumuşak doku prosedürü ve tamamı polietilen patellar implant ile revizyonu sonrası tanjansiyel grafide patellanın femoral olukta olduğu görülmektedir (b).

edilmesi, uygun dış rotasyonda yapılan kesinin bir göstergesidir. Osteoartrozlu dizlerde bilgisayarlı tomogra$\mathrm{fi}$ (BT) ile yapılan simülasyon çalışmasında $1^{\circ}$ ye kadar dış rotasyonda kelebek bulgusu, 2-3 ${ }^{\circ}$ kesilerde kuyruklu piyano bulgusu, $1-2^{\circ}$ dış rotasyonda kesilerde ise bot bulgusu'nun görüldüğü belirtilmiştir. ${ }^{[23]}$ Ayrıca, femoral oluk anatomik olarak femoral orta hattın yaklaşık 2,5 mm lateralinde yer alır. Simetrik kondiller tasarımlı protezler anatomik olarak yerleştirildiğinde, femoral oluğun bu konumu kaybedilir, femoral oluk mediyalize olur, $\mathrm{Q}$ açısında ve lateral vektörde artış olabilir.

Patellanın laterale yetersiz devrilmesi, posterolateral tibial platoya yaklaşımı güçleştirir. Buna bağlı olarak $\mathrm{da}$, tibial komponent iç rotasyonda ve mediyalize yerleştirilebilir. Bu durum, tibial tüberkülün lateralize olmasına ve $\mathrm{Q}$ açısında artışa neden olur. Operasyon sırasında gerekli işaretleme yapılarak tibial komponentin merkezi, tibial tuberkülün mediyal üçte birlik kısmına denk gelecek şekilde ayarlanmalıdır. Patellar komponentin mediyalize yerleştirilmesi ve lateral faset ile distal kutup rezeksiyonundan kaçınılması önerilmektedir.

Komponentlerin doğru yerleştirilmesi PFi'yi önlediği gibi, lateral retinakuler gevşetme ihtiyacını, dolayısı ile patellar kırık oluşum riskini de azaltır. Patellar implantın ve femoral komponentin yüksekliği de lateral retinakuler gerginliğe neden olabilmektedir. Operasyon sırasında patellar gezinimin (tracking) değerlendirilmesinde turnikenin indirilmesi daha doğru sonuçlar vermektedir. Yüz hasta ile yapılmış bir çalışmada, turnikenin indirilmesinin 16 hastadan beşinde (\%31) lateral gevşetme ihtiyacını engellediği belirtilmiştir. ${ }^{[24]}$ PFi'ye neden olan en önemli yumuşak doku dengesizliği, lateral retinakuler gerginliktir. Her zaman söylendiği gibi, TDA, kemik kesilerinin ve komponent yerleştirilmesinin yapıldığı basit bir marangozluk işlemi değil, öncelikle bir yumuşak doku cerrahisidir. ${ }^{[25]}$ TDA operasyonu sonrası yetersiz cerrahi kapamaya, hematom oluşumuna, yoğun fizyoterapi uygulanmasına veya travmaya bağlı mediyal retinakuler zayıflık gelişebilir. Eğer mediyal laksite ile patellar subluksasyon gelişirse, cerrahi tedavi ile mediyal yapıların onarımı gerekebilir.

\section{Önlem}

Ameliyat öncesi risk faktörleri olan olgularda, kemik kesilerinde ve yumuşak doku dengesinde gerekli modifikasyonlar yapılmalı ve cerrahi sırasında patellar gezinim sık sık değerlendirilmelidir. Cerrahi sırasında, deneme komponentleri yerleştirildikten sonra patellar gezinimin güvenilirliği (başparmak desteği bulgusu / no thumb sign) kontrol edilmeli; şüphe varsa, nihai implantlar yerleştirilmeden önce komponentlerin dizilimi değerlendirilmeli, gerekirse yeniden düzenlenmeli; implantlar yerleştirildikten sonra patellaya lateralden destek hala gerekli görünüyorsa, lateral retinakuler gevşetme ile yumuşak doku dengesi sağlanmaya çalışılmalıdır. Patellar gezinimi doğru değerlendirmek için turnikenin serbestleştirilmiş olmasına dikkat edilmelidir.

\section{Tanı}

Hastanın muayenesi sırasında, hareket açıklığı boyunca palpe edilerek subluksasyon veya çıkık tespit edilebilir. Ayrıca hastanın ön-arka, yan ve tanjansiyel diz radyografileri, hatta gereklilik halinde BT ile, komponent yerleşimine ilişkin bozukluklar ve patellar instabilite tespit edilebilir (Şekil 1). 

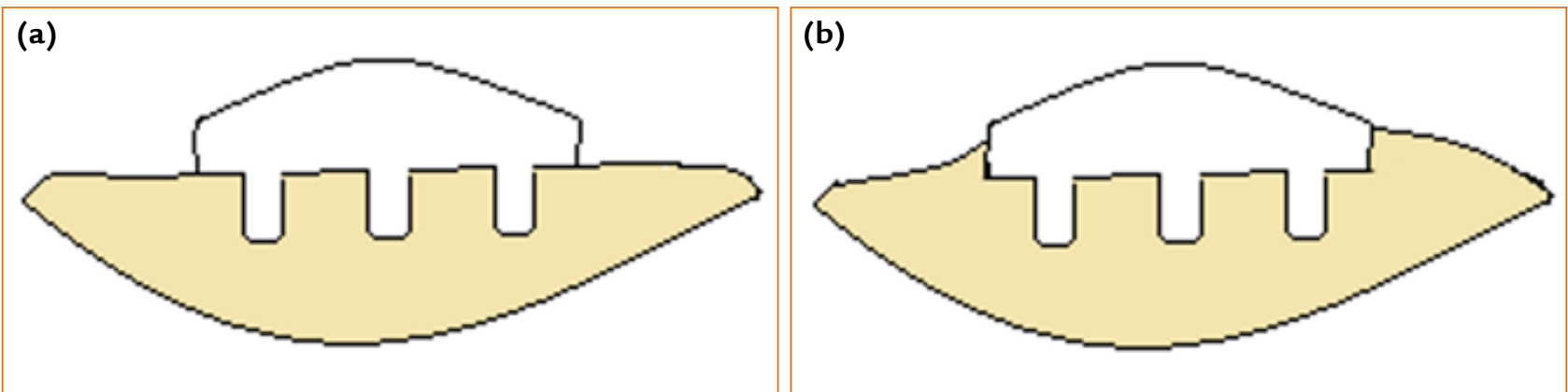

Şekil 2. a, b. Onset patellar implant uygulaması (a). Inset patellar implant uygulaması (b).

\section{Tedavi}

TDA sonrasında belirgin bir PFi geliştiğinde, genellikle konservatif tedavi yöntemleri başarılı olmamaktadır. Ancak, herhangi bir cerrahi girişime başvurmadan önce bir süre denenebilir. Bu amaçla, kuadriseps güçlendirme egzersizleri ve breyslerden yardım alınması, instabiliteyi arttıran aktivitelerden kaçınılması yararlı olabilir. Zamanla retinakuler dokularda skar dokusunun gelişerek yakınmaların yatışmasını sağlaması umulur.

Sınırlı yumuşak doku cerrahi girişimleri (örn., lateral retinakuler gevşetme) cazip görünmekle birlikte soruna kalıcı ve yeterli bir çözüm çoğunlukla sağlamamaktadır. Cerrah, ameliyat öncesi dönemde de PFi olan bir olguda kombine yumuşak doku ve kemik cerrahi işlemlerine; dizilim kusuru ve komponent yerleşim bozukluklarının neden olduğu belirlenen cerrahi kökenli PFI'lerde her üç komponentin de revizyonuna hazırlıklı olmalıdır. Spesifik etiyolojik faktör belirlenerek, ona yönelik cerrahi tedavi uygulanması en başarılı sonuçları vermektedir. ${ }^{[26]}$ Eğer herhangi bir komponent pozisyon sorunu ya da ekstremite dizilim sorunu ortaya konamıyorsa, lateral retinakuler gevşetme (gerekirse proksimal ve distal dizilim düzeltici girişimlerle de desteklenerek) uygulanabilir. Ancak, daha önceki bölümlerde de belirtildiği üzere, bu tür olgularda nüks ve re-operasyon riski yüksek görünmektedir. ${ }^{[6]}$ Ayrıca, lateral retinakuler gevşetmenin tümüyle benign bir işlem olmadığı, ekstansör mekanizma komplikasyonlarını (patellar kırık, gevşeme) arttırabileceği de akılda tutulmalıdır.

\section{PATELLAR IMPLANT YETMEZLIĞi VE AŞINMASI}

Günümüzde TDA teknik ve tasarımındaki gelişmeler sayesinde, erken tasarım TDA'larda yüksek oranda görülen patellar komponentin aşınması, gevşemesi gibi sorunlarla çok daha az karşılaşılmaktadır. Bugün bu tür komplikasyonlarla karşılaşılmasının başlıca nedeni implantın kendisi olmayıp, komponentlerin yerleşiminde yapılan hatalardır. Bunlar arasında sıklıkla; yetersiz patellar kemik stoğuna bağlı yerleştirme ve tespit sorunları, patellar komponentin uygun yerleştirilmemesi, patellar dizilim bozukluğu, asimetrik patellar kemik kesisi ve yerleştirme, patellar osteonekroz, çimentosuz implantlar üzerine yeterli kemik ilerlemesi olmaması vb. yer almaktadır.

Her ne kadar patellar komponent, tibial komponent kadar aşınmaya maruz kalmasa da, onun dayanıklılığını arttırmaya yönelik arayışlar da sürmektedir. Yüksek çapraz bağlı polietilen veya E-vitamini ile güçlendirilmiş polietilen patellar komponentler bu amaçla geliştirilmiştir. Ancak, bu tür patellar komponentlerin kullanımının klinik sonuçlara yansıması henüz gösterilememiştir.

Geçmişte diğer bazı anatomik bölgelerdeki başarıI uygulamalar nedeniyle patellada da denenen metal arkalıklı patellar komponentler, anatomik ve mobil patellar komponentler, çıkardıkları sorunlar nedeniyle günümüzde terk edilmişlerdir. Günümüzde, en iyi sonucu veren, tümüyle polietilenden oluşan patellar komponentler kullanılmaktadır. Yine bir süre kullanımda olan tek santral pegli patellar komponentler de, yüksek gevşeme oranları nedeniyle bugün yerlerini tümüyle üç pegli implantlara bırakmıştır.

Patellar komponentin implantasyonunda inset (gömme) veya onlay (yüzeyin tam restorasyonu) teknikleri uygulanabilir (Şekil 2). Inset tekniği ile implantın tespit alanındaki dayanıklıı̆̆ının daha fazla olduğu gösterilmiştir. ${ }^{[27,28]}$ Ayrıca, bu teknikle patellanın kemik stoğu ve vaskülaritesi de daha iyi korunabilir ve patellar komponentin sementsiz olarak uygulanması mümkün olabilir. Nihayet inset teknikle yerleştirilen patellar komponentli olgularda patella üzerindeki stres, implant ve patellanın geri kalan yüzeyi tarafından paylaşılır. Böylece 

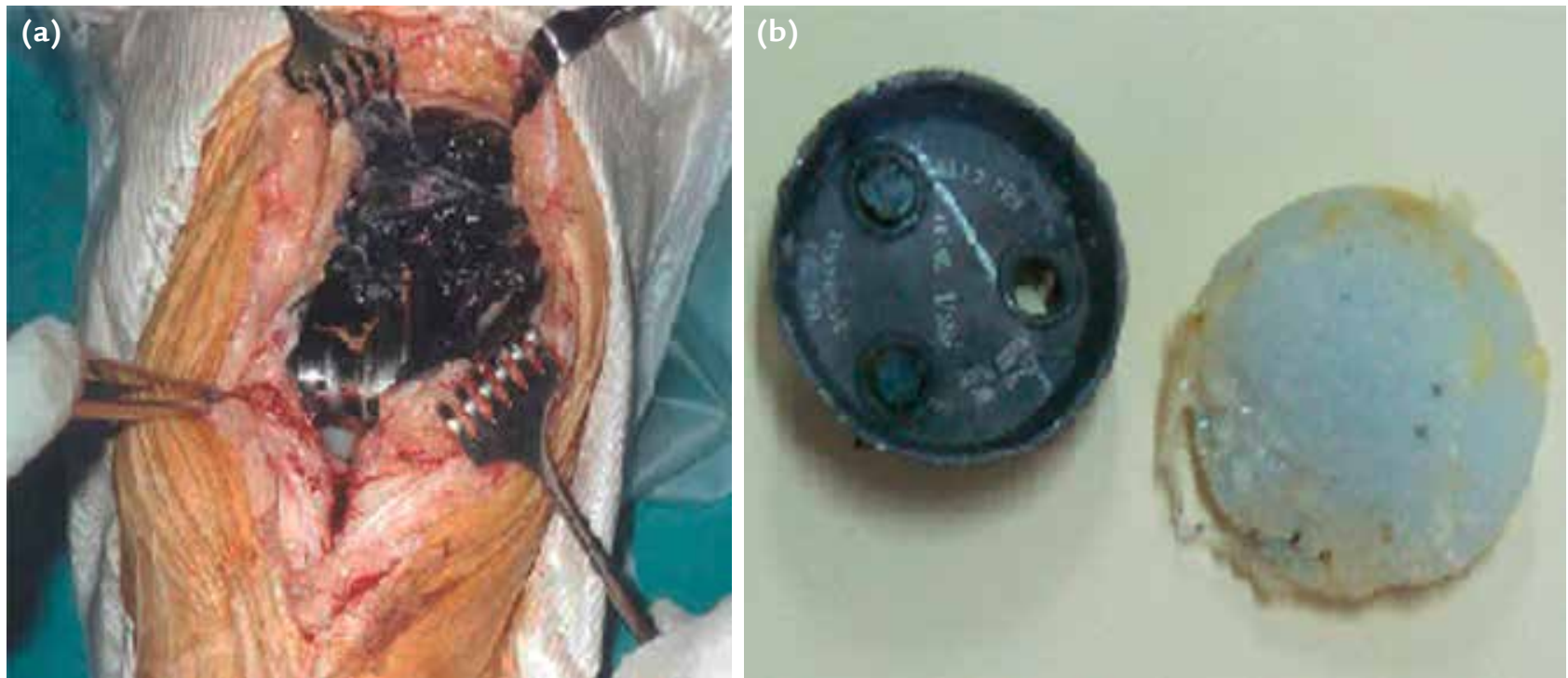

Şekil 3. a, b. Metal arkalıklı patellar implantın yetmezliği sonrasında patellar komponentin metal kısmının femoral kondile sürterek meydana getirdiği metalloz cerrahi sırasında gösterilmiştir (a). Aşınmış patellar implant (b).

PFE üzerindeki yüklenme geniş bir alana dağıtılarak azaltılmış olur.

Patellar implantlarda oluşan yıpranma ve yetmezliklerin, daha çok gezinim bozukluğu ya da kayma (maltracking) problemi olan hastalarda PFE'de artmış stres ile ilişkili olduğu yukarıda belirtilmişti. Tibiofemoral eklemdeki aşınmanın aksine, oluşan fibrozis, stabiliteyi arttırması nedeni ile daha az revizyona neden olmaktadır. Bir zamanlar çok popüler olan metal sırtlı implantlarda daha ince polietilen komponent kullanılması, implantın daha kolay ve hızla aşınmasına neden olarak alttaki metal parçanın açığa çıkmasına, femoral komponente sürtünerek birbirlerini aşındırmasına ve metalloz gelişimine neden olmaktaydı (Şekil 3). Bu tasarımların terkedilmesiyle birlikte, günümüzde patellar komponent aşınma ve gevşeme sorunları artık hemen daima komponent yerleşim ve dizilim bozukluğu olgularında görülmektedir.

Tibiofemoral eklemdeki başka bir sorun ya da enfeksiyon nedeniyle revizyon işlemi uygulanan TDA'larda, revizyon sırasında hangi teknik uygulanmış olursa olsun, patellar komponent ve çevresinin metalik femoral komponent ile teması sonucu yoğun bir fibröz doku ile örtülü olduğu görülmektedir. Böylesi bir dokunun gelişimi; patellar komponentin stabilitesine katkıda bulunmakta, aşınma ve gevşeme gibi sorunlardan korunmasına yardımcı olmaktadır.

Eğer revizyon işlemi sırasında patellar kemik stoğu yeterli bulunursa, patellar komponent bir başka komponent ile revize edilmektedir; kemik stoğu çimento kullanılmasına rağmen tespite izin vermeyecek kadar bozulmuş ise, bir tür rezeksiyon artroplastisi ya da fibröz doku interpozisyon artroplastisi ile herhangi bir komponent yerleştirilmeden boş bırakılmaktadır.

\section{PATELLANIN ASEPTIK NEKROZU}

Patellanın aseptik nekrozu kendini inatçı diz ağrısı veya sekonder patellar kırık ile gösterebilir. Tanı amacı ile çekilen ön-arka, yan ve aksiyel plandaki konvansiyonel radyografilerde, patellada skleroz, yassılaşma ve parçalanma tespit edilebilir. Erken tanıda sintigrafi ve manyetik rezonans (MR) görüntüleme yardımcıdır. Asemptomatik olan olguların çokluğu nedeni ile TDA sonrası aseptik nekroz oranı tam olarak tespit edilememektedir.

Patellanın intra-osseöz kanlanması; suprema genikuler arter (SGA) ile mediyal/lateral superior genikuler arterler (MSGA/LSGA) ve mediyal/lateral inferior genikuler arterler (MiGA/LiGA) ve nihayet anterior tibial rekurren arterin (ATRA) patella etrafında oluşturduğu halka tarafından sağlanır. Bu vasküler halka, dorsal ve radyal arterler ile patellaya bağlanır. Peripatellar anastomotik halkanın ve özellikle patella alt kutbunun radyal arteriyel beslenme nedeni ile korunması gerekmektedir. Operasyon sırasında mediyal artrotomi ile SGA, SMGA ve IMGA, lateral retinakuler gevşetme ile SLGA ve ILGA, lateral menisektomi ile ATRA ve ILGA, infrapatellar yağ yastığının 


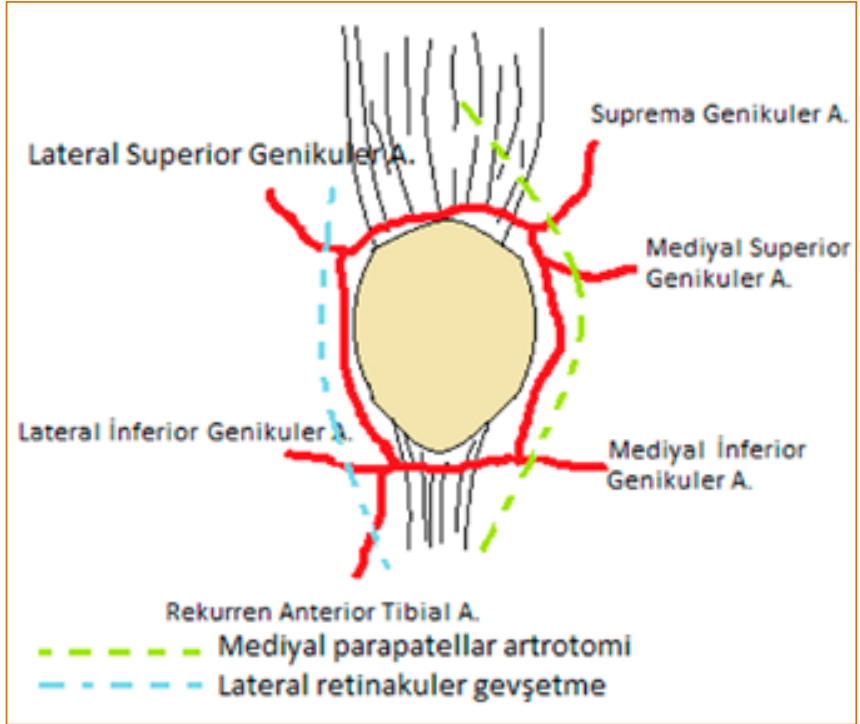

Şekil 4. Patellanın kan desteği, mediyal parapatellar artrotomi ve lateral retinakuler gevşetme sırasında zarar gören vasküler yapılar.

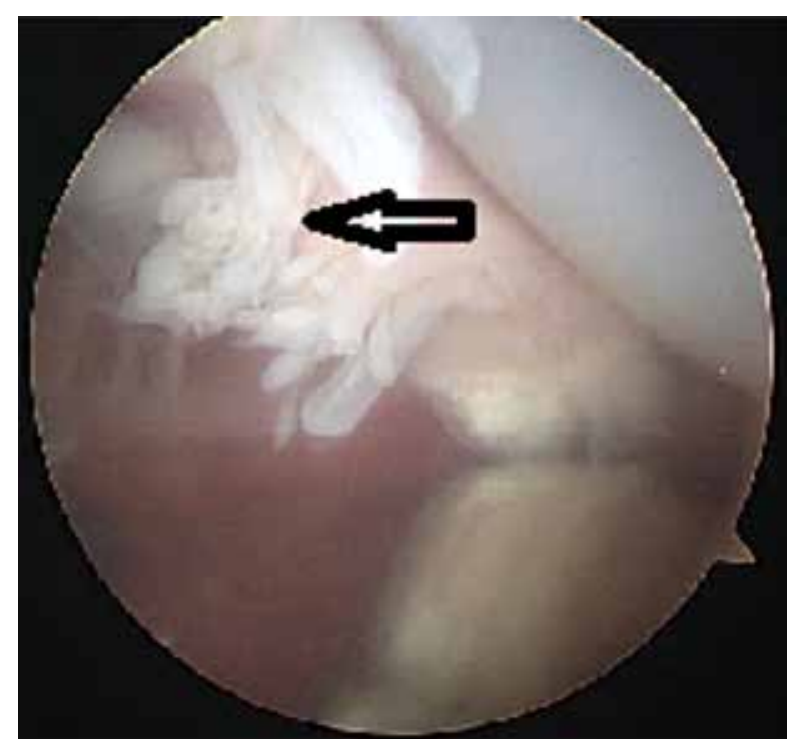

Şekil 5. Patello-femoral "clunk" sendromu nedeni ile artroskopik debridman uygulanan dizde patellanın üst kutbunda fibrotik doku. uzaklaştırılması ile ATRA ve ILGA zarar görebilmektedir (Şekil 4). ${ }^{[29]}$ Lateral retinakuler gevşetme uygulanmış 36 hastanın ameliyat sonrası sintigrafi ile değerlendirildiği bir çalışmada, hipovaskülarite oranı 3,95 kat artmış olarak bulunmuştur. ${ }^{[30]}$

Tedavi planlaması semptom varlığı ve patellar komponent stabilitesine dayanmaktadır. Ayrıca, patellar komponentin revizyonu veya sadece patellar komponent ile kemik parçalarının eksizyonu kararı patellar kemik stoğuna göre verilmelidir. Semptom yokluğunda girişim gerekmez.

\section{PATELLO-FEMORAL “CLUNK” SENDROMU VE KREPITASYON}

"Clunk" sendromu ile, primer olarak posterior stabilizan TDA tasarımlarında karşılaşılmaktadır. Patellanın üst kutbunda gelişen fibrosinoviyal hiperplazik doku, dizin ekstansiyonu sırasında femoral komponentin interkondiller çentik bölgesine takılarak, hareketin devamında değişen derecelerde ağrılı kurtulma hissine neden olur. Temel etiyoloji olarak yüksek anterior yerleşimli interkondiller çentik, femoral komponentin fleksiyonda ve büyük boy oluşu, tibial komponentin anterior yerleşimi, patella baja, eklem çizgisinin değişmesi suçlanmaktadır. Fleksiyonun erken aşamalarında kuadriseps tendonu femoral komponentin yüksek interkondiller çentiğine temas etmektedir. Bu nedenle, tipik olarak primer
TDA uygulamasından sonraki ilk bir yıl içinde, dizin aktif ekstansiyonu sırasında ve diz yaklaşık $30^{\circ}$ fleksiyondayken görülebilen-duyulabilen bir "clunk" ile karakterizedir. Ayrıca, büyük boy ve fleksiyonda yerleştirilmiş femoral komponentten de mantık olarak kaçınılmalıdır. Eklem çizgisinin değişmemesi ve göreceli olarak patella baja oluşmaması için operasyon sırasında aşırı distal femoral kesi yapılmamalıdır. Kaplanmamış patellar kemiğin femoral komponente temas etmemesi ve patella baja oluşmaması için, patellar komponentin kendisi de mümkün olduğunca yukarıya yerleştirilmelidir. Üst kutba çok yakın yerleştirilmiş patellar komponentin de kuadriseps tendon irritasyonuna neden olup krepitasyon ve patellofemoral clunk oluşturma riski bulunmaktadır. ${ }^{[31]}$ Yine, femoral komponentte troklear oluğun kısa tutulmak yerine uzatılması gibi tasarım düzenlemeleri de bu komplikasyonun görülme sıklığını düşürmektedir.

Bekleme, kuadriseps egzersizleri ve intra-artikuler steroid enjeksiyonu ile, olguların ancak \%20'sinde sonuç alınabilmektedir. Patellofemoral clunk sendromunun tedavisi için uygulanan, artroskopik veya açık yöntemle lokalize hiperplazik dokunun eksizyonu ise yüksek oranda başarılı sonuç vermektedir (Şekil 5). ${ }^{[31]}$

Diz hareketleri sırasında patella çevresinde duyulabilen veya hissedilebilen bir krepitasyon varlığı; patellar gezinimdeki bozukluklara ve femoral komponent tasarımına bağlanmaktadır. Eğer beraberinde ağrı yoksa, bu tür yakınmaların sadece izlenmesi yeterli olacaktır. 


\section{SONUÇ}

Yaşlılıkta diz ekstansör mekanizmasından yeterli verimi alabilmek için, TDA uygulaması sırasında patellanın eskimiş yüzeyini değiştirmek, mantıksal olarak tartışılmaması gereken bir konu olmalıdır. Cerrahlar, patellar eklem yüzeyinin değiştirilmesi hususunda "Cinderella"yı oynamamalıdır. ${ }^{[32]}$ Bugün için, TDA sırasında zaman kazanma ve sonraki bazı komplikasyonlardan kaçınma amaçlarıyla patellar yüzey değişiminden kaçınılması, elde edilen sonuçların kalitesindeki kayıp yüzünden kabul edilebilir olmaktan uzaktır. Her halükarda, TDA'nın bu önemli parçası, başarılı bir TDA sonucu için yeterli zaman ve özen harcanmasını hak etmektedir.

Yüzey değişimi uygulanan patellanın ameliyat öncesi kalınlığının korunması ve uygun bir komponent yerleşimi sağlanmalıdır. Küçük boy ve inset yöntemle yerleştirilmiş bir patellar komponent, patellanın kemik stoğunu ve vaskülarizasyonunu daha iyi koruyabilecektir. Subvastus yaklaşımının tercih edilmesi de, kuadriseps kasının gücünü, propriyosepsiyonunu ve yine patellanın vaskülarizasyonunu koruyarak, karşılaşılabilecek sorunları asgari seviyeye indirecektir.

Sonuç olarak; günümüz TDA tasarımlarında, TDA uygulaması sırasında tam doğrulukla patellar rezeksiyonun yapılması, patellar dolaşımın korunması, TDA'nın tüm komponentlerinin uygun şekilde yerleştirilmesi, yumuşak doku "impingement"ının önlenmesi ve merkezi patellar gezinimin sağlanması, PFE kökenli komplikasyonlar yönünden cerrahi tekniğe ilişkin başlıca önlemleri oluşturmaktadır.

\section{KAYNAKLAR}

1. Vince KG. The problem total knee replacement: systematic, comprehensive and efficient evaluation. Bone Joint J 2014;96$B(11$ Suppl A):105-11. Crossref

2. Doolittle KH 2nd, TurnerRH. Patellofemoral problems following total knee arthroplasty. Orthop Rev 1988;17(7):696-702.

3. Bozic KJ, Kamath AF, Ong K, Lau E, Kurtz S, Chan V, Vail TP, Rubash $H$, Berry DJ. Comparative Epidemiology of Revision Arthroplasty: Failed THA Poses Greater Clinical and Economic Burdens Than Failed TKA. Clin Orthop Relat Res 2015;473(6):2131-8. Crossref

4. Sadoghi $P$, Liebensteiner $M$, Agreiter $M$, Leithner A, Böhler $N$, Labek G. Revision surgery after total joint arthroplasty: a complication-based analysis using worldwide arthroplasty registers. J Arthroplasty 2013;28(8):1329-32. Crossref

5. Parker DA, Dunbar MJ, Rorabeck CH. Extensor Mechanism Failure Associated With Total Knee Arthroplasty: Prevention and Management. J Am Acad Orthop Surg 2003;11(4):23847. Crossref

6. Cooney WP 4th, Sierra RJ, Trousdale RT, Pagnano MW. Revision total knees done for extensor problems frequently require reoperation. Clin Orthop Relat Res 2005;440:11721. Crossref
7. Helmy N, Anglin C, Greidanus NV, Masri BA. To resurface or not to resurface the patella in total knee arthroplasty. Clin Orthop Relat Res 2008;466(11):2775-83. Crossref

8. Calvisi V, Camillieri G, Lupparelli S. Resurfacing versus nonresurfacing the patella in total knee arthroplasty: a critical appraisal of the available evidence. Arch Orthop Trauma Surg 2009;129(9):1261-70. Crossref

9. Agrawal $M$, Jain V, Yadav VP, Bhardwaj V. Patellar resurfacing in total knee arthroplasty. J Clin Orthop Trauma 2011;2(2):77-81. Crossref

10. Fu Y, Wang G, Fu Q. Patellar resurfacing in total knee arthroplasty for osteoarthritis: a meta-analysis. Knee Surg Sports Traumatol Arthrosc 2011;19(9):1460-6. Crossref

11. He JY, Jiang LS, Dai LY. Is patellar resurfacing superior than nonresurfacing in total knee arthroplasty? A meta-analysis of randomized trials. Knee 2011;18(3):137-44. Crossref

12. Greene KA, Schurman JR 2nd. Quadriceps muscle function in primary total knee arthroplasty. J Arthroplasty 2008;23(7 Suppl):15-9.e2. Crossref

13. Fraser J, Spangehl MJ. International rates of patellar resurfacing in primary total knee arthroplasty 2004-2014. J Arthroplasty 2017;32(1):83-6. Crossref

14. Tang X, Wang J, Dong P, Zhou R. A Meta-Analysis of Patellar Replacement in Total Knee Arthroplasty for Patients With Knee Osteoarthritis. J Arthroplasty 2018;33(3):960-7. Crossref

15. Longo UG, Ciuffreda M, Mannering N, D'Andrea V, Cimmino $\mathrm{M}$, Denaro V. Patellar resurfacing in Total Knee Arthroplasty: Systematic Review and Meta-Analysis. J Arthroplasty 2018;33(2):620-32. Crossref

16. Peterson W, Rembitzki IV, Brüggemann GP, Ellermann A, Best R. Gösele-Koppenburg A, Liebau C. Anterior knee pain after total knee arthroplasty: a narrative review. Int Orthop (SICOT) 2014;38(2):319-28. Crossref

17. Becher C, Heyse TJ, Kron N, Ostermeier S, Hurschler C, Schofer MD, Fuchs-Winkelmann S, Tibesku CO. Posterior stabilized TKA reduce patellofemoral contact pressure compared with cruciate retaining TKA in vitro. Knee Surg Sports Traumatol Arthrosc 2009:17(10);1159-65. Crossref

18. Li N, Tan Y, Deng Y, Chen L. Posterior cruciate-retaining versus posterior stabilized total knee arthroplasty: a metaanalysis os randomized controlled trials. Knee Surg Sports Traumatol Arthrosc 2012;22(3):556-64. Crossref

19. Toro-Ibarguen AN, Navarro-Arbias R, Pretel-Mazzini J, PradaCanizares AC, Jara-Sanchez F. Secondary Patellar Resurfacing as a Rescue Procedure for Persistent Anterior Knee Pain After Primary Total Knee Arthroplasty: Do Our Patients Really Improve? J Arthroplasty 2016;31(7):1539-43. Crossref

20. Malo, M, Vince, KG. The unstable patella after total knee arthroplasty: Etiology, prevention, and management. J Am Acad Orthop Surg 2003;11(5):364-71. Crossref

21. Berger RA, Rubash HE, Seel MJ, Thompson $W H$, Crossett LS. Determining the rotational alignment of the femoral component in total knee arthroplasty using the epicondylar axis. Clin Orthop Relat Res 1993;(286):40-7. Crossref

22. Fehring TK. Rotational malalignment of the femoral component in totaL knee arhroplasty. Clin Orthop Relat Res 2000;380:72-9. Crossref

23. Cui WQ, Won $\mathrm{Y}$, Baek MH, Kim KK, Cho JH. Variations of the "grand piano sign" during total knee replacement. J Bone Joint Surg Br 2006;88-B(11):1441-7. Crossref

24. Husted $\mathrm{H}$, Jensen $\mathrm{TT}$. Influence of the pneumatic tourniquet on patella tracking in total knee arthroplasty. 2005;20(6):694-7. Crossref 
25. Motsis EK, Paschos N, Pakos EE, Georgoulis AD. review article: patellar insitability after total knee arthroplasty. J Orthop Surg 2009;17(3):351-7. Crossref

26. Nam D, Abdel MP, Cross MB, LaMont LE, Reinhardt KR. The management of extensor mechanism complications in total knee arthroplasty: AAOS Exhibit selection. J Bone Joint Surg Am 2014;96(6):e47. Crossref

27. Rosenstein AD, Postak PD, Greenwald AS. Fixation strength comparison of onlay and inset patellar implants. Knee 2007;14(3):194-7. Crossref

28. Hurson C, Kashir A, Flavin R, Kelly I. Routine patellar resurfacing using an inset patellar technique. Int Orthop 2010;34(7):955-8. Crossref
29. Lazoro EL, Cross MB, Lorich DG. Vascular anatomy of the patella: implications for total knee arthroplasty surgical approaches. Knee 2014;21(3):655-60. Crossref

30. Pawar U, Rao KN, Sundaram PS, Thilak J, Varghese J. Scintigraphic assessment of patellar viability in total knee arthroplasty after lateral release. J Arthroplasty 2009;24(4):636-40. Crossref

31. Conrad DN, Dennis DA. Patellofemoral crepitus after total knee arthroplasty: etiology and preventive measures. Clin Orthop Surg 2014;6(1):9-19. Crossref

32. Mendes DG, Fraenkel P. Patella or not? Is the patella component the 'Cinderella' of total knee arthroplasty? Knee 2000;7(4):205-6. Crossref 